\title{
Prevalence of Bovine Fasciolosis in Selected Dairy Farms of Addis Ababa, Ethiopia
}

\author{
Dereje Berhanu and Gebrehiwot Tadesse* \\ College of Veterinary Medicine, Mekelle University of Ethiopia (*tadesse498@yahoo.com).
}

\begin{abstract}
A cross sectional study is carried out in selected dairy farms in and around Addis Ababa on the prevalence of fasciolosis in Ethiopia, in four sub-cities, locally called Kifele Ketemas. The dairy farms were under intensive and semi-intensive management systems. A total of 384 cattle were randomly selected and sampled which accounts for 95\% (N=365) and 5\% (N=19) of the samples for intensive and semi-intensive dairy farms, respectively. Fecal samples were examined using the direct fecal microscopic examination and Benedict's sedimentation tests. Out of 384 samples examined, 57 samples were found to be positive using both tests, giving a prevalence of $14.84 \%$ $(\mathrm{N}=57)$. The prevalence of fasciolosis in study areas (Kifele Ketemas) is $52.63 \%(\mathrm{~N}=30)$ in Yeka, 33.33\% ( $\mathrm{N}=19)$ in Bole, 10.35\% $(\mathrm{N}=6)$ in Gullele and 3.51\% ( $=2)$ in Kality area. The prevalence of bovine fasciolosis in Yeka is significantly higher $(\mathrm{P}<0.05)$ than in the other three sub-cities. Statistically significant deference is observed $(\mathrm{P}<0.05)$ among sexes, $44.44 \%(\mathrm{~N}=4)$ in males and semi-intensively managed cattle $63 \%(\mathrm{~N}=12)$. The overall infection prevalence is higher $(20.37 \%)(\mathrm{N}=33)$ in animals categorized under body condition score (BCS) 2 than animals categorized under body condition score 3, 4, and 5. BCS 2 accounts for $20.37 \%$ (N=33) of the total positive animals, BCS 3 accounts for $7.19 \%(\mathrm{~N}=11)$, BCS 4 accounts for $17.77 \%$ $(\mathrm{N}=8)$ and BCS 5 accounts for $20.83 \%(\mathrm{~N}=5)$ of the total animals sampled. No statistically significant difference $(\mathrm{P}>0.05)$ is observed between the age groups.
\end{abstract}

Keywords: Bovine; Fasciolosis; Prevalence; Chi-square; Addis Ababa; Ethiopia.

\section{INTRODUCTION}

Fasciolosis is a serious infectious parasitic disease infecting domestic ruminants and humans, tops all the zoonotic helminthes worldwide (Haridy et al., 2002). A large variety of animals like sheep, goats, cattle, buffalo, horses, donkeys, camels and, rabbits, show infection rates that may reach 90\% in some areas (Farag, 1998). According to World Health Organization report (WHO, 2007), the infection was limited in the past to specific and typical geographical areas but is now widespread throughout the world, with human cases being increasingly reported from Europe, the Americas, and the Oceania and from Africa and Asia. Fasciolosis is endemic in 61 countries and has become a food-borne infection of public health importance in parts of the world such as the Andean Highlands of Bolivia, Ecuador, and Peru; the Nile Delta of Egypt and northern Iran. 
It is estimated that more than 180 million people are at risk due to this infection, and infection rates are high enough to make fasciolosis a serious public health concern (WHO, 1998).

Fasciolosisis one of the most prevalent parasitic diseases in the cattle in Ethiopia (Manyazewal et al., 2014). The disease is also found in sheep and goats (Andrews, 1999) and occasionally affects human beings (Okewole et al., 2000; WHO, 1995). The common determinant factors for survival of metacercaria and intermediate host are- temperature, humidity and slowly moving water. Ineffectiveuse of anthelmintic, poor management system and health awareness of the society have been found to have a great impact on the prevalence of bovine. This paper presents the results of the study carried out to determine the prevalence of fasciolosis in bovine and its association with different socio-economic factors.

\section{MATERIALS AND METHODS}

\subsection{Description of the Study Area}

The study was conducted in Addis Ababa city veterinary laboratory centerin AddisAbaba $\left(9^{0}\right.$ 2' 'N and $38^{0} 42^{\prime}$ 'E, $640 \mathrm{~m}^{2}$ area, $2500 \mathrm{~m}$.a.s.1), Ethiopia. The area receives an average annual rainfall of about $1164 \mathrm{~mm}$. The annual mean minimum and maximum temperatures during the study period were $6^{0} \mathrm{C}$ and $24^{\circ} \mathrm{C}$ respectively. Livestock population in the area during the study time wasestimated about 65,568 cattle (CSA, 2015). Four Kifele Ketemas: Yeka, Gullele, Kaliti and Bole were selectedfor the study of population of bovines. The sample size for estimating the prevalence of fasciolosisin bovine was obtained by simple random sampling without replacement of the variation coefficient at 10\% (Cochran, 1963). From each herd, $20 \%$ of the animals were selected randomly.A total of 384 animals, consisting of male and female were selected through cross sectional approach from farms in the four sub-cities in and around Addis Ababa. Out of 384 cattle sampled, 9 were males and 375 females.

About two grams of feces was collected into labeled test tubes containing $3 \mathrm{~mL}$ of distilled water. The fecal samples and the distilled water were strained to give a suspension. The suspension was strained through a tea strainer into a corresponding cleaned labeled petridish. The filtrate was poured into corresponding test tubes. One milliliter of $10 \%$ formalin was added to the test tubes and allowed to stand for 10 minutes. Diethyl-ether $(1 \mathrm{~mL})$ was added to the test tubes after 10 minutes, using different 18-gauge hypodermic needle and syringe. The test tubes containing the 
suspension were then corked, shaken to mix and centrifuge at $2000 \mathrm{rpm}$ for 8 minutes. The eggs and cysts of the parasites sediment at the bottom and the faecal debris became separated in a layer between the dietyl-ether and water. The supernatant was then decanted leaving few of it with the sediment (Benedict,1946). Two drops of the sediment were put on a glass slide, covered with cover slip, and viewed under microscope using x100 magnification. In addition, secondary data was also collected from commercial dairy farm owners and also small scale farmers using pre-tested semi-structured questionnaire for information regarding production/economic loss due to parasitic diseases, particularly fasciolosisand related veterinary services. The data was recorded on specially designed forms and preliminary analysis was done in Microsoft ${ }^{\circledR}$ Excel $^{1}$ 2007. The outcome variables were the positive cases of fasciolosisdetected during the fecal examination of the same. Data analysis was made using chi-square statistical analysis technique.

\section{RESULTS}

384 faecal samples from adult cattle were examined for the presence of fasciola eggs. Out of these, $14.84 \%(n=57)$ were found positive and presence of fasciola eggs. The prevalence of bovine fasciolosis infour study areas, Yeka, Bole, Kaliti and Gullele is 52.63\% ( $\mathrm{N}=30), 33.33 \%$ $(\mathrm{N}=19), 10.53 \%(\mathrm{~N}=6)$ and $3.51 \%(\mathrm{~N}=2)$, respectively. The prevalence of fasciolosis in males is $44.44 \%(\mathrm{~N}=4)$ which is significantly higher $(\mathrm{p}<0.05)$ compared to females, which is $14 \%$ $(\mathrm{N}=53)$. Furthermore, semi-intensively managed cattle have significantly higher prevalence $63 \%$ $(\mathrm{N}=12)(\mathrm{p}<0.05)$ than the cattle managed in fully intensive management system $11 \%(\mathrm{~N}=36)$.

Table 1. Prevalence of bovine fasciolosis.

\begin{tabular}{|lllllllll|}
\hline $\begin{array}{l}\text { Study } \\
\text { Area }\end{array}$ & \multicolumn{2}{c}{$\begin{array}{c}\text { Management } \\
\text { System }\end{array}$} & \multicolumn{2}{c}{ Sex } & & Age & $\begin{array}{l}\text { Total } \\
\text { Animals }\end{array}$ & $\begin{array}{l}\text { Prevalence } \\
\text { in \% }\end{array}$ \\
\cline { 2 - 7 } & $\begin{array}{l}\text { Intensive } \\
\text { (n=327) }\end{array}$ & $\begin{array}{l}\text { Semi } \\
\text { intensive } \\
(\boldsymbol{n}=\mathbf{1 9})\end{array}$ & Female & Male & Adult & Calf & & \\
\hline Yeka & 20 & 10 & 28 & 2 & 26 & 4 & 178 & 52.63 \\
\hline Bole & 17 & 2 & 17 & 2 & 19 & 0 & 103 & 33.33 \\
\hline Gullele & 6 & 0 & 5 & 1 & 6 & 0 & 96 & 10.53 \\
\hline Kaliti & 2 & 0 & 2 & 0 & 2 & 0 & 7 & 3.51 \\
\hline Total & 45 & 12 & 52 & 5 & 53 & 4 & 384 & 14.84 \\
\hline
\end{tabular}


In addition, the prevalence of fasciolosisbetween female and male animals varied significantly $(\mathrm{p}<0.05)$ where male cattle having significantly higher prevalence than female cattle.

Table 2. Prevalence of fasciolosisin cattle in relation to sex:

\begin{tabular}{|lllllr|}
\hline Sex & Total Examined & Positive & Negative & Prevalence in \% & p-value \\
\hline Female & 375 & 53 & 322 & 14.13 & \\
\hline Male & 9 & 4 & 5 & 44.44 & 0.020 \\
\hline
\end{tabular}

Management system, climatic conditions and sources of feed, like hay, are found to have significant relation with the occurrence of bovine fasciolosis in the study areas (Table 3).

Table 3. Prevalence of fasciolosis in relation to management systems of study cattle:

\begin{tabular}{|llllllc|}
\hline Management System & Yeka & Bole & Gullele & Kaliti & Prevalence \% & P-value \\
\hline Semi-intensive & 35 & 24 & 0 & 0 & 15.34 & \\
\hline Intensive & 143 & 79 & 96 & 7 & 84.84 & 0.012 \\
\hline Total & 178 & 103 & 96 & 7 & 14.84 & \\
\hline
\end{tabular}

Prevalence of cattle fasciolosis is found to be significantly higher in the cattle with body condition score 2 as compared to the prevalence of cattle having body condition scores 3,4 and 5 respectively.

Table 4. Prevalence of fasciolosis in relation to body condition scores of cattle examined.

\begin{tabular}{|l|l|l|l|l|}
\hline Rank & $\begin{array}{l}\text { Total number of animals under } \\
\text { each body condition score }\end{array}$ & $\begin{array}{l}\text { Number of } \\
\text { positive } \\
\text { animals }\end{array}$ & $\begin{array}{l}\text { Percent } \\
\text { positive animals }\end{array}$ & -value \\
\hline Score 2 & 162 & 33 & 20.37 & 0.035 \\
\hline Score 3 & 153 & 11 & 7.19 & \\
\hline Score 4 & 45 & 8 & 17.78 & \\
\hline Score 5 & 24 & 5 & 20.83 & \\
\hline
\end{tabular}

Statistical analysis of the data revealed significant association $(\mathrm{p}<0.05)$ between infection with the parasite and sex. Though, the number of male cattle examined is only 9 compared to 375 female cattle. 


\section{DISCUSSION}

The study has revealed the prevalence of fasciolosisin the cattle reared in and around Addis Ababa city. Disease prevalence is found variable among the four sub-cities, Yeka, Bole, Kaliti and Gullele. Water logging conditions, poor drainage network, acidic soils in highlands are some of the factors that often cause endemic for fasciolosis(Brook et al., 1985;Mulat et al., 2012). In the study area, irrespective of the seasons and topography of the grazing land, the highest prevalence $(\mathrm{p}<0.05)$ of fasciolosis is recorded in Yeka sub-city. Thus, the climatic factors in Yeka appears to be more favorable for the propagation and activity of the snail, the intermediate host of fasciola and progression of the parasitic life cycle throughout the year, when compared to the sub-cities, Bole, Gullale and Kaliti. Prevalence in male though is significantly higher $(\mathrm{p}<0.05)$ compared females, this observation needs some more data as only 9 male were examined compared to 375 female. It may be due to the presence of favorable environmental, climate and topography of the land. Thus, the availability of water was found to be responsible for the increased seasonal prevalence of fasciolosisin four areas. This is in sharp contrast with the findings of Magaji et al. (2014) who reported significantly higher prevalence of infection of fasciolosisin male than in female cattle $(\mathrm{p}>0.05)$. Non-significant difference among sex on prevalence of fasciolosis was also reported by Mahidere et al. (2017) which contradicts with the present study. The possible explanation could be the fact that the data on male cattle is limited. Moreover, it could also depend on whether both male and female cattle are exposed equally to grazing land or fed on the same type of hay. Statistically significantly higher prevalence of fasciolosis was recorded in cattle with body condition score 2 . The possible explanation could be that cattle with poor body condition have lower immunity and thus more susceptible to the parasitic infection of fasciolosis. Consequently, these cattle could be anemic due to migrating young fasciola parasites thus damaging the veins and arteries. Ultimately, cattle with poor body condition may lose appetite and as a result loss of body weight leading to poor body condition score (Terefe et al., 2012).

The prevalence of fasciolosis among cattle is attributed to the climatic condition which does favor the survival of the intermediate host, the snail as inthe case of Yeka sub-city. Lower prevalence of fasciolosis infection in Kaliti and Gullele can be attributed to the climatic conditions which do not favor the survival of the intermediate host, the snail. This intermediate 
host prefers swampy areas with slowly moving water and small streams which also allow sufficient moisture for the survival of the infective metacercariae. On the contrary, Gullele and Kaliti areas do not have swampy areas that favor the intermediate host, the snail. This probably explains the lower prevalence of fasciolosis infection among the cattle in these areas.

Snail habitat is one of the most important factors that influence the occurrence of fasciolosis in an area (Urquhart et al., 1996). In the present case, cattlemayalso have the probability to get infected by feed (hay) which is harvested from localities in which intermediate host snail is known to exist. In addition, optimal temperatures i.e. $10^{\circ} \mathrm{C}$ and $16^{\circ} \mathrm{C}$ which are necessary for survival of the snail as hosts of Fasciolahepatica and Fasciolagigantic respectively also available in some of the study areas. The ideal moisture conditions for snail breeding and development of larval stages of snail are provided when rainfall exceeds transpiration and field saturation. Such conditions are also essential for the development of fluke eggs, miracidiae searching for snails and for the dispersal of cercariae (Urquhart et al., 1996). Of the total number of faecal samples examined $14.83 \%$ of them were found to be positive for bovine fasciolosis. Due to the reason that the bionomic requirements for breeding of the Lymnaea snails and developing of the interimolascan stages of the fluke often reach the optimum threshold during the wet months of the year. During dry periods, breeding of the snails and development of the larval flukes slow down or stops completely and snails undergo a state of aestivation (Yilma and Malone, 1998). In addition, the existence of permanent suitable ecological conditions in areas like slow flowing rivers, streams and man-made water areas may contribute to the persistent but relatively low grade infection during dry season (Magaji et al., 2014).It is thus, concluded that fasciolosis infection of cattle exists in all four sub-cities irrespective of the environmental differences. This parasitic disease is also capable of infecting both sexes although in different proportion. Nationwide study is recommended parallel to the education of cattle owners to deworm their cattle regularly and to prevent environmental factors that favor snails to inhabit.

\section{ACKNOWLEDGEMENTS}

The authors are grateful to all Dairy farm owners who participated in the study and provided us access to take samples for the research work. Further, we would like to thank College of Veterinary Medicine of Mekelle University for providing the necessary financial support. 


\section{REFERENCE}

Andrews, S.J. 1999. The life cycle of Fasciola hepatica. In: Fasciolosis, J. P. Dalton (ed.). CABI Publishing, Walling Ford, UK, pp1-30.

Benedict, L. 1946. Examination of liver fluke eggs with sedimentation technique. Allatorvlapok, 66:139-140.

Brook Lemma, Fisseha Gabreab \& Shibru Tedla. 1985. Studies on fasciolosis in four selected sites in Ethiopia. Veterinary Parasitology, 18: 29-37.

Cochran, W. G. 1963. Sampling Techniques, 2. Aufl. John Wiley and Sons, New York. 159p.

CSA (Central Statistical Authority). 2015. Livestock and Livestock Characteristics. Agricultural Sample Survey 2014/2015 (2008 E.C) Report (Private Peasant Holdings), Central Statistical Authority, Federal Democratic Republic of Ethiopia, Addis Ababa, $120 \mathrm{p}$.

Farag H.F. 1998. Human fasciolosis in some countries of the Eastern Mediterranean Region. Eastern Mediterranean Health Journal, 4(1): 156-160.

Haridy, F.M., Morsy, T. A., Gawish, N. I., Antonios, T. N \& Ahdel Gawad, A.G. 2002. The potential reservoir role of donkeys and horses in zoonotic fasciolosis in Gharbia Governorate, Egypt. Journal of the Egyptian Society of Parasitology, 32(2): 561-570.

Magaji, A. A., Ibrahim, K., Salihu, M.D., Saulawa, M.A., Mohammed, A.A \& Musawa, A. I. 2014. Prevalence of Fasciolosis in cattle slaughtered in Sokoto Metropolitan Abattoir, Sokoto, Nigeria. Advance in Epidemiology. Article ID247258, http.//dx.doi.org/10.1155/2014/247258, 5p.

Mahidere, M., Tsegabirhan, K., Niguse, A \& Niraji, K. 2017. Study on Prevalence of Bovine Fasciolosis and Its Economic Impact at Sheno Municipal Abattoir, North Shewa, Ethiopia. Ethiopian Journal of Vet. Science and Animal Production, 1(1): 35-45.

Manyzewal, A.Z., Gurnesa, M \& Tesfaye, T. 2014. Economic Significance of Fasciolosis at Mettu Municipal Abattoir, Southwest Ethiopia. Journal of Advanced Veteterinary Research, 4(2): 53-59.

Mulat, N., Basaznew, B., Mersha, C., Ashenafi, M \& Tewodros, F. 2012. Comparison of coprological and postmortem examination techniques for the determination fo 
prevalence and economic significance of bovine Fasciolosis. Journal of Advanced Veterinary Research, 2:18-23.

Okewole, E.A., Ogundipe, G.A.T., Adejinmi, J.O \& Olaniyan, A.O. 2000. Clinical Evaluation of three chemo prophylactic regimes Ovine Helminthosis in a fasciola Endemia farm in Ibadan, Nigeria. Israel Journal of Veterinary Medicine, 56 (1): 15-28.

Terefe, D., Wondimu, A \& Gachen, D.F. 2012. Prevalence, gross pathological lesions and economic losses of bovine Fasciolosis at Jimma Municipal Abattoir, Ethiopia. Journal of Veterinary Medicine and Animal Health, 4(1): 6-11.

Urquhert, G.M., Duncan, J.L., Amour, J.A.M \& Jennings. 1996. Veterinary Parasitology.

WHO. 1995. Control of food borne Trematode infections. Technical report series 849, 61p.

WHO. 1998. Triclabendazole and fasciolosis- a new drug to combat an age-old disease. Fact Sheet no. 191.

WHO. 2007. Report of the WHO Informal Meeting on use of triclabendazole in fasciolosis control. Technical Report WHW/CDC/NTD/PCT/2007.1.

Yilma, J \& Malone, J.B. 1998. A geographical information system forecast model for strategic control of Fasciolosis in Ethiopia. Ethiopian veterinary Journal, 1(3): 12-18 